\title{
TERCEIRIZAÇÃO EM INFORMÁTICA NO BRASIL
}

Jaci Corrêa Leite

Professor do Departamento de Informática $e$ Métodos Quantitativos da EAESP/FGV.

RESUMO: Este trabalho descreve uma pesquisa de campo feita no Brasil em 1995. Foram consultadas 125 empresas para investigar aspectos ligados a motivações para terceirizar em informática, os mecanismos pelo quais esse processo se materializa, os resultados alcançados e os problemas enfrentados como conseqüência desta opção. São revelados alguns importantes aspectos, até então pouco conhecidos, sobre esta realidade no contexto brasileiro.

ABSTRACT: This text describes an empirical research conduced in Brazil in 1995, comprehending 125 companies, in order to investigate why they outsource information technology services and the process used to implement it, as well as the resulting goals reached and the difficulties faced. Some important aspects, before roughly known, were now revealed, helping to understand this issue in Brazilian context.

PALAVRAS-CHAVE: informática, terceirização, administração de sistemas de informação, gestão de informática, outsourcing.

KEY WORDS: information systems, information systems management, information technology management, outsourcing. 


\section{INTRODUÇÃO}

Assim como muitas outras atividades e serviços, a informática tem demonstrado forte tendência de ser transferida para terceiros. Mas, ao contrário do que ocorre na maioria dos demais casos, a terceirização em informática apresenta condiçōes peculiares: aqui, devido aos riscos envolvidos, o custo deixa de ser o principal critério de decisão e, no seu lugar, entram avaliações inerentemente subjetivas.'

A primeira grande experiência com terceirização, feita pela Kodak em $1989,{ }^{2}$ foi recebida com ceticismo por uns, ira por outros e surpresa por todos. Desde então, muitas outras empresas têm trilhado este mesmo caminho aberto pela Kodak. Algumas o têm feito de uma maneira mais suave: ao invés de transferirem integralmente a responsabilidade para parceiros externos, apenas terceirizam alguns nichos e continuam mantendo uma área própria, interna, de informática.

Hoje em dia ainda restam controvérsias sobre a conveniência ou não de terceirizar. Muitos advogam a tese de que este caminho não só é positivo como também virtualmente irreversível, pelo menos num horizonte de médio prazo, ${ }^{3}$ enquanto que outros questionam severamente sua eficácia, alegando inclusive que se trata de uma atitude de altíssimo risco. ${ }^{4}$

Contando com o financiamento do NPP - Núcleo de Pesquisas e Publicações da EAESP/FGV, a pesquisa de campo aqui relatada foi conduzida ao longo de 1995, visando compreender mais de perto esta realidade, particularmente no contexto brasileiro. Para isto foram observadas, através de questionário, 125 empresas de todos os portes e ramos de atividades, focalizando os diversos aspectos relacionados à terceirizaçăo em informática. Para assegurar que a pesquisa cobriria os principais pontos relevantes, o questionário foi elaborado com base na bibliografia disponível. $^{5}$

\section{A AMOSTRA}

O universo desta pesquisa é composto de empresas de todos os setores, inclusive alguns órgãos públicos e sociedades de economia mista.

Com faturamento anual médio em torno de US $\$ 400$ milhões (mínimo de US $\$ 400$ mil e máximo de US $\$ 7$ bilhões), as organizações pesquisadas podem ser consideradas como um bom referencial para empresas médias e grandes. E, como se pode confirmar nos gráficos da figura 1, a amostra é bastante diversificada em termos de organização societária, origem do capital predominante, faturamento anual e setor de atividade. Em outras palavras, é representativa da realidade brasileira e as observações aqui encontradas podem ser tomadas como um bom padrão de comparação.

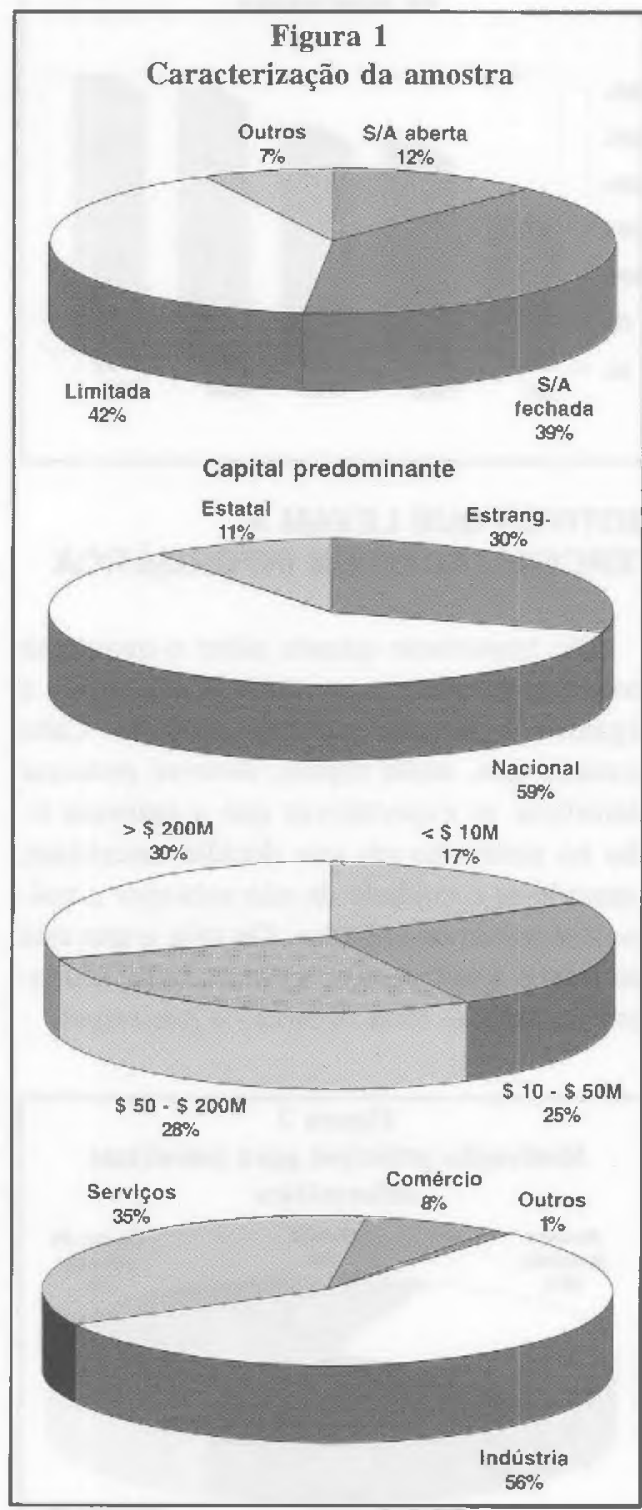

\section{RESULTADOS OBSERVADOS}

Ainda que em pequena escala, $80 \%$ das empresas pesquisadas declararam terceirizar serviços de informática. Buscou-se então identificar qual é a parcela terceirizada, medida
1. LEITE, Jaci Corrèa. Terceirizacão em informática. São Paulo: Makron Books. 1994.

2. KEYES, Jessica, Infotrends - the competitive use of information. New York USA: MçGraw-Hill, 1993.

3. CHAVES, Sidney. Terceirizacão das ativldades de Informática. Beel/ne y. 1 , n. 11, dez. 1992, p. 3-4: LEITE, Jaci Corrêa. Op. cit.: MCFARLAN, F. Warren \& NOLAN Richard L. How to manage an IT outsourcing alliance. h sloan Management Review. Winter 1995, p. $g$ 23.

4. WANG, Charles B. O novo papel do executivo de informática. São Paulo. Makron Books, 1995

5. COOPERS \& LIBRAND. A terceinzação nas empresas. 2a Pesquisa Coopers \& Librand, Sāo Paulo, 19פ2; LACITY, Mary Cecella \& HIRSCHHEIM, Rudy. Information Systems Outsourcing. England: John Wiley \& Sons, Chichester, 1993; CHAVES Sidney. Para onde caminha a tecnologia da informação. Beeline. y. 3, ก. 7. jul. 1994 p. 3·6. LEITE, Jaci Corrêa. Op. cit. 
em termos de participação no orçamento total da área de informática. Com base na evolução mostrada na figura 2, pode-se constatar que a terccirização tem crescido a taxas moderadas mas seguras, com uma aparente tendência de estabilizar-se em torno de $30 \%$ do orçamento global de informática.

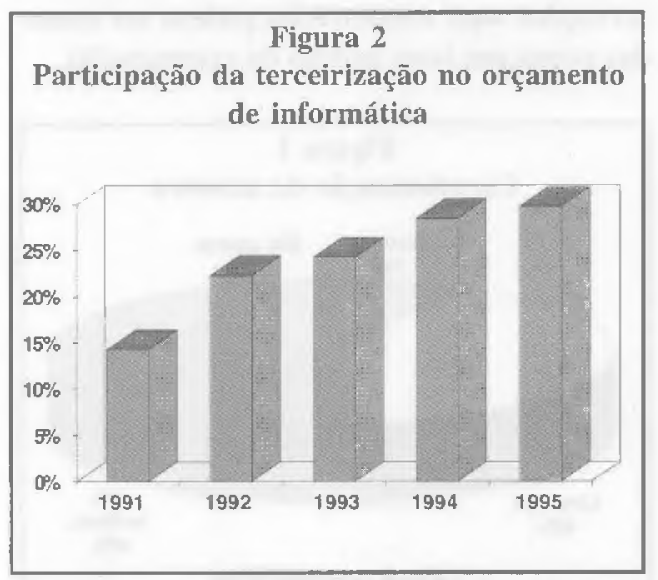

\section{MOTIVOS QUE LEVAM À TERCEIRIZAÇÃO EM INFORMÁTICA}

Tão importante quanto saber o quanto se terceiriza é conhecer os motivos que levam a organização a optar por este caminho. Cabe destacar que, neste tópico, deve-se procurar identificar as expectativas que a empresa titha no momento em que decidiu terceirizar, tomando-se o cuidado de não sobrepor a análise dos resultados obtidos. Ou seja, o que está em jogo é a perspectiva ex ante, independentemente do que teria ocorrido a posteriori.

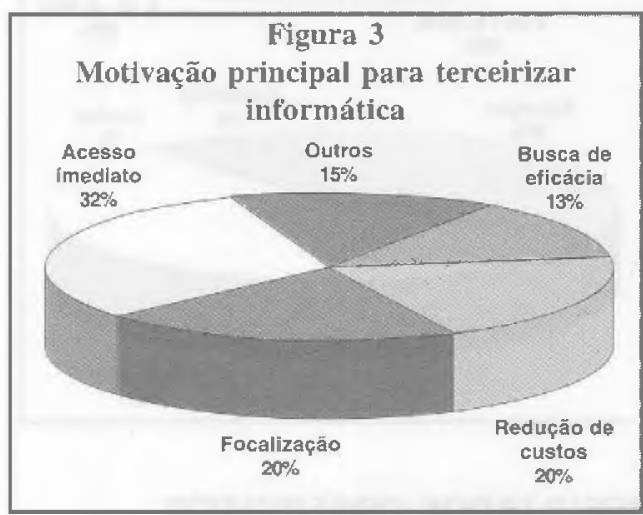

Ao se perguntar às empresas qual foi a principal razão que as levou a terceirizar em informática, a motivação mais frequientemente apontada não foi, como usualmente se presume, a perspectiva de redução de custos. O principal motivo foi o acesso imediato a novos recursos, sejam eles físicos ou humanos. Estas empresas terceirizam em informática principalmente porque têm a percepçāo de que, sem isto, dificilmente conseguirão aquilo que buscam. Devese destacar, inclusive, que foram identificados vários casos de empresas cujos primeiros passos na informática foram dados através da telceirização, aumentando ainda mais a participação relativa desta resposta.

Num segundo patamar aparecem duas outras motivações, cada uma com $20 \%$ das respostas: a focalização (ou seja, a concentração nas atividades-fim da empresa) e a expectativa de redução de custos.

Vale ainda notar a busca por eficácia, citada em $13 \%$ dos casos. A empresa por vezes percebe que, com sua própria equipe interna, dificilmente conseguirá romper a inércia do status quo. Por isto, acaba correndo o risco de buscar, com a ajuda de parceria externa, um fôlego renovado para os sistemas de informação.

Quanto à rubrica "Outros", embora somando $15 \%$, é resultado de respostas esparsas, nenhuma delas superior a $3 \%$.

\section{COMO SE IMPLEMENTA A TERCEIRIZAÇÃO EM INFORMÁTICA}

Uma outra questão relevante diz respeito à forma e ao ritmo segundo o qual se implementa a terceirização em informática, chegando-se ao resultado observado na figura 4 .

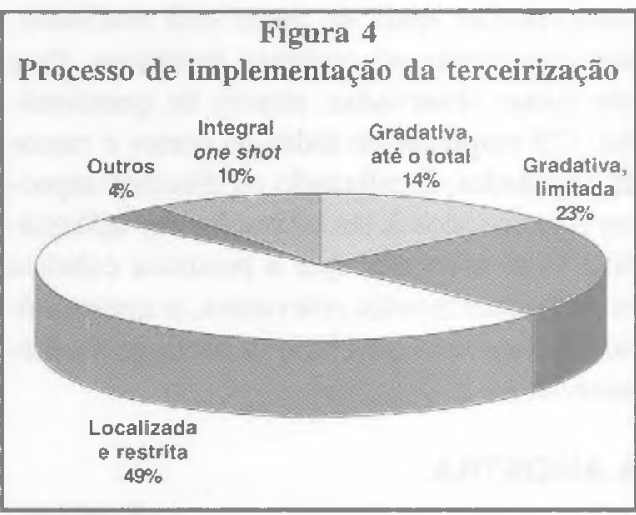

Confome declararam quase metade das empresas, nota-se que o mais comum é que a terceirização fique sujeita a nichos mais ou menos restritos, por vezes (mas nem sempre) previamente definidos.

Outra experiência, vivida por pouco me- 
nos de um quarto das empresas, é a implementação gradativa, mas sem intenção de chegar à transferência total de responsabilidades. É comum terceirizar, de início, apenas um nicho (de preferência, o de menor risco). Depois, à medida que se gaanha maior confiança, estende-se gradativamente a terceirização para novas atividades, que muitas vezes sequer foram previamente definidas.

Dessas duas respostas mais citadas, podese deduzir que praticamente três quartos das empresas não consideram provável que venham a atingir a terceirização total, nem mesmo numa perspectiva de longo prazo.

Chama a atenção, ainda, o fato de que quase um quarto das empresas da amostra já chegaram ou pretendem chegar à terceirização total. Algumas fazem isto através de um processo one shot, terceirizando tudo de uma vez. Outras optam pela via do gradualismo, mas também pretendem, ao fim de algum tempo, chegar à terceirização total. Apesar disto, parece evidente que o padrão do mercado está mais para uma solução híbrida, uma terceirização seletiva, na qual ainda não se sente a confiança suficiente para eliminar de vez a área interna de informática. E, conforme se verá mais adiante, talvez existam bom motivos para essa insegurança.

\section{POLÍTICA COM RELAÇÃO À QUANTIDADE DE PARCEIROS}

Num processo de terceirização em informática, o primeiro dos quatro fatores críticos de sucesso é a definição do nível de terceirização, ou seja, o grau em que a empresa pretende transferir, para parceiros externos, seus serviços de informática. Esta definição é essencial. A busca de parceiros, por mais criteriosa que seja, pode resultar em sérios erros se não houver uma definição clara de até aonde se pretende chegar. Sem esta base, a contratação de parceiros transformase num processo fragmentado e confuso, muitas vezes empregando critérios conflitantes. ${ }^{6}$

Na presente pesquisa, este assunto foi abordado através da existência ou não de uma política com relação à quantidade de parceiros. A perspectiva de terceirização mais intensa recomenda maior concentração no número de parceiros, priorizando aqueles que possam oferecer ampla gama de serviços.

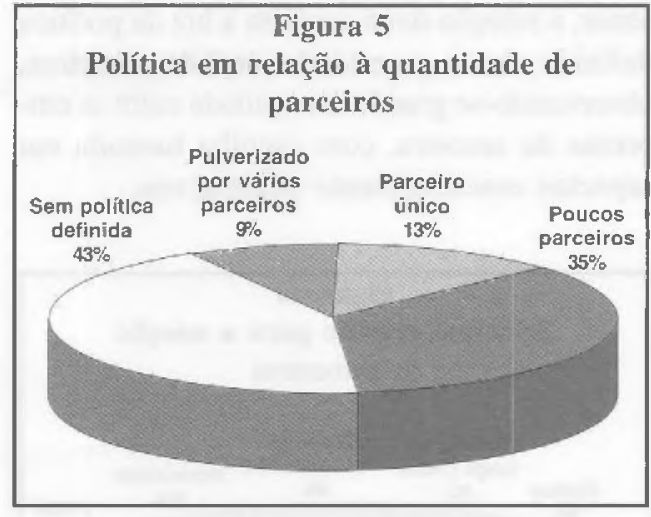

Idealmente, a definição da quantidade de parceiros deveria anteceder $o$ início do processo de contratação de prestadores de serviços. A figura 5 mostra, porém, que a realidade brasileira está longe do ideal: quase metade das empresas consultadas não tem nenhuma política definida com relação à quantidade de parceiros.

Essa situação parece ser indício de falta de maturidade da terceirização no contexto brasileiro. As respostas sugerem que, na prática, a posição quanto ao número de parceiros vem sendo tomada após o início do processo. Tal indefinição pode levar a desagradáveis imprevistos. Por exemplo, se depois de algum tempo decide-se trabalhar com poucos parceiros e o processo já havia sido iniciado sem considerar este aspecto, será preciso rever todos os contratos anteriormente entregues a prestadores de serviços pouco diversificados, possivelmente redirecionando-os para um ou dois novos parceiros. Como qualquer rompimento tende a ser uma experiência ruim, este é um caso típico de problema que poderia ser facilmente evitado.

Por outro lado, nota-se que quase metade prefere trabalhar com um ou poucos parceiros (aparentemente, a situação menos problemática), enquanto que apenas $9 \%$ optam pela pulverização dos serviços. Esta última postura, geralmente adotada em nome da segurança, costuma ser arriscada: no mais das vezes, a pulverização traz grande complexidade administrativa, sem acrescentar de fato nenhuma independência em relação aos parceiros.

\section{CRITÉRIOS PARA A ESCOLHA DE PARCEIROS}

A escolha do parceiro é o segundo fator crítico para o sucesso da terceirização em informática. ${ }^{7}$ Conforme explicado no tópico an- o. LEITE, Jaci Corrêa. Op. cit.

7. Idem, ibidem. 
terior, a seleção deve ser feita à luz da política definida para a quantidade ideal de parceiros, observando-se grande diversidade entre as empresas da amostra, com escolha baseada em aspectos essencialmente qualitativos.

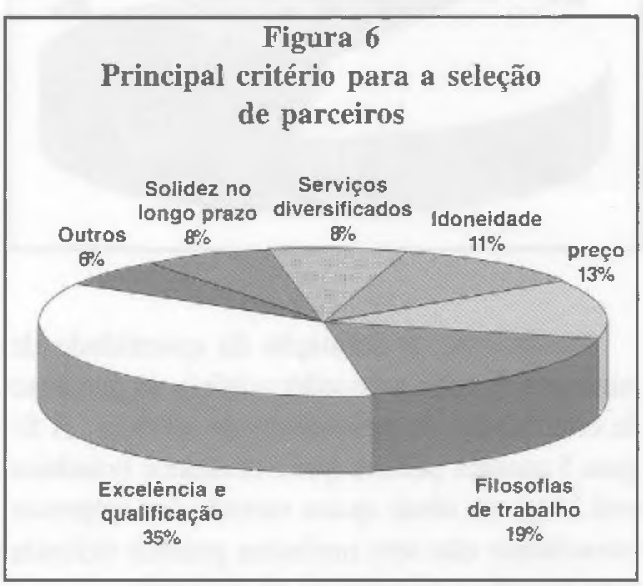

A figura 6 mostra que o critério de seleção mais comum, adotado por pouco mais que um terço das empresas, é a excelência e qualificaçāo do parceiro, isto é, sua efetiva capacidade de propor e implementar soluções.

Uma em cada cinco empresas usa, como principal critério para escolher o parceiro, a compatibilidade entre as filosofias de trabalho. Ou seja, dá-se preferência ao prestador de serviços que tenha visões similares sobre metodologias, documentação, segurança e outros aspectos considerados relevantes, caso a caso, pela empresa contratante.

Apenas uma em cada oito empresas julga que o preço seja fator primordial. Isso geralmente está associado a serviços que possam ser enquadrados como commodities (por exemplo, digitação).

A idoneidade do parceiro vem logo atrás, sendo o requisito principal para uma em cada nove empresas. Dois outros fatores merecem menção. $O$ primeiro deles é a preferência por parceiros capacitados a oferecer uma ampla gama de serviços, opção certamente associada à intenção de terceirizar em larga escala. O segundo é a solidez do parceiro e suas perspectivas a longo prazo, o que revela a preocupação de buscar relacionamentos estáveis.

\section{TRATAMENTO DISPENSADO AO PESSOAL TÉCNICO INTERNO}

nico como do usuário, é apontada como o terceiro fator crítico para o sucesso da terceirização em informática. ${ }^{8}$ Via de regra, processos de terceirização costumam ocorrer num clima emocionalmente carregado, não só entre os técnicos, mas até mesmo entre os usuários.

Os problemas com o pessoal técnico e com o usuário são de naturezas diferentes. O usuário, habituado a relacionamentos subjetivos com seus colegas da área de informática, precisa aprender a tratar com parceiros externos, uma situação nova, em que a divisão de responsabilidades tende a ser mais objetiva. Isso normalmente requer mudanças de comportamento que, em geral, levam um bom tempo até que sejam absorvidas.

No caso dos técnicos, a situação é mais delicada, pois será preciso definir qual será o seu destino. Essa é uma situação que não chegou a ser enfrentada por todas as empresas da amostra, visto que algumas delas deram seus primeiros passos na informática já através da terceirização e, portanto, não tinham uma equipe própria com que se preocupar.

Naturalmente, este é um caso típico de soluções híbridas, com várias possibilidades sendo aplicadas simultaneamente, caso a caso: um é dispensado, outro é reaproveitado em novas funções, outro vai trabalhar com o parceiro e assim por diante. Porém, este levantamento pedia que fosse apontado, em resposta única, o encaminhamento mais usual, chegando-se ao resultado mostrado na figura 7 .

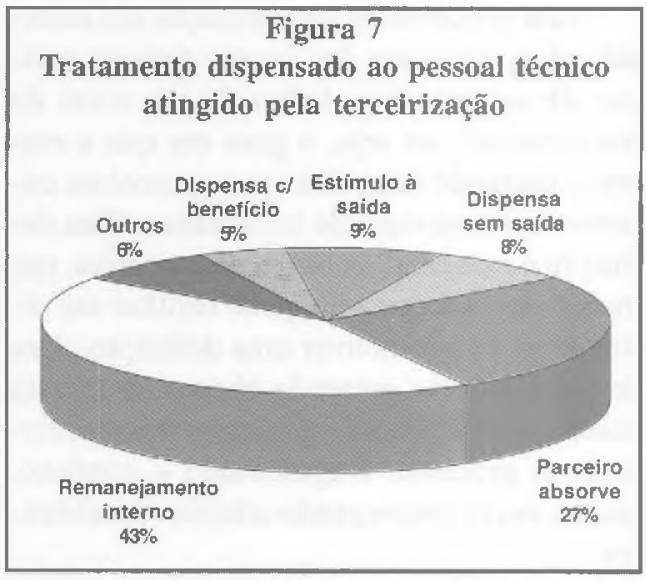

Dentre as empresas que enfrentaram o problema, a solução mais usual foi preservar os técnicos, remanejando-os internamente para novas funções. Isso não parece coerente com a percepção generalizada de que, consumada a terceirizaçăo, a equipe inter- 
na (ou pelo menos grande parte dela) perde seus empregos. Restam, portanto, duas hipóteses: ou a percepção do desemprego é exagerada ou, o que parece mais provável, as empresas pesquisadas evitaram admitir que dispensam seu pessoal durante a terceirização.

A segunda solução mais mencionada, preferida por um quarto das empresas, é transferir o corpo técnico para o parceiro. Essa prática, relativamente recente, era quase inexpressiva há alguns anos e, provavelmente, continuará crescendo, por ser uma solução confortável para todos os envolvidos: o parceiro externo absorve know-how rapidamente e com baixo investimento, a empresa que terceiriza não precisa arcar com o desgaste das demissões, e os técnicos passam a ter novas oportunidades de carreira, por vezes, muito mais motivadoras do que antes. ${ }^{9}$

As empresas pesquisadas relatam ainda o estímulo à saída (os chamados planos de demissão voluntária), a dispensa sem benefícios (em que se paga estritamente a indenização determinada por lei) e a dispensa com benefícios (quando o empregado recebe vantagens além das obrigatórias).

\section{REDAÇÃO DO CONTRATO}

A redação do contrato de prestação de serviços é um dos principais focos de atrito nas parcerias. Cláusulas escritas nem sempre refletem adequadamente as percepçōes das partes mas, como existe uma situação formalizada, fica difícil rever os termos do acordo. Por vezes, há mútuas acusações de má fé quando, na verdade, o produto final não foi corretamente especificado, principalmente no que diz respeito a qualidade e niveis de serviço. Por isso, a redação do contrato é o quarto e último fator crítico para o sucesso da terceirização em informática. ${ }^{10}$

Há várias abordagens a partir das quais é possivel redigir o contrato inicial:

- pode ser proposto pelo parceiro, que possui o chamado contrato de adesão (padronizado), ao qual todos os clientes devem se sujeitar;

- pode ser proposto pela contratante que, por vezes, tem um contrato-padrão, ao qual devem sujeitar-se todos os seus prestadores de serviços;

- pode ser elaborado pela área jurídica da empresa contratante, com ênfase maior nos aspectos legais;

- pode ser elaborado pela área técnica da empresa contratante, priorizando os requisitos técnicos e a descrição detalhada dos serviços;

- pode combinar duas ou mais das abordagens acima.

Em qualquer dos casos, normalmente há um certo grau de flexibilidade que depende, em última instância, do poder de barganha de cada parte. A figura 8 mostra a distribuição das diversas possibilidades.

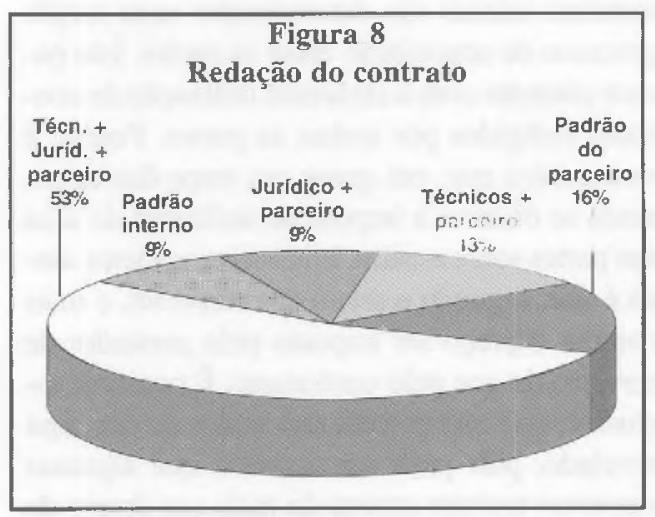

Mais da metade das empresas relatam que o contrato é fruto de trabalho a seis mãos (parceiro, área jurídica e área técnica), demonstrando a tendência de maior maturidade nos relacionamentos. É bom lembrar que não só o instrumento contratual em si é importante: o próprio processo de discussão e negociação, através de aproximações sucessivas, é que vai pacientemente moldar a relação de parceria. Por isto, em casos de terceirização mais ampla, o processo de delinear o contrato pode levar meses e chega a ser mais importante que o próprio documento em si."

\section{DETERMINAÇÃO DOS PREÇOS E CONDIÇÕES INICIAIS}

Embora o custo de serviços de informática não deva ser o centro das atenções, a definição dos preços iniciais pode ser um jogo de forças ou o início do aprendizado de convivência. Se um dos dois lados faz valer seu poder para determínar o preço a ser pago pelos serviços, tem-se, no mínimo, um mau começo para uma relação de parceria que se deseja duradoura.
9. LEITE, Jaci Corrêa. Op. cit.

10. MCFARLAN \& NOLAN. Op. cit. 11. CHAVES, Sidney. Op. cit, 1994

RAE • v. 37 - n. 3 - Jul./Set. 1997 


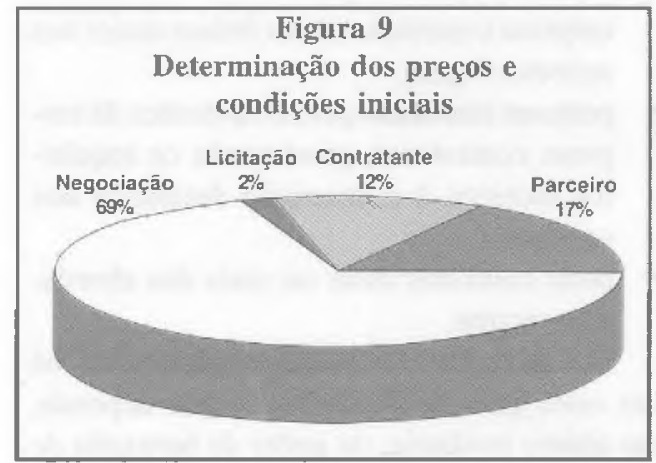

A figura 9 mostra que sete em cada dez empresas declaram que os preços e condições comerciais iniciais são determinados num amplo processo de negociação entre as partes. Isto parece coerente com a crescente utilização de contratos redigidos por ambas as partes. Porém, é sintomático que, em quase um terço dos casos, ainda se observa a imposição unilateral de uma das partes sobre a outra. Mais surpreendente ainđa é que, segundo o relato das empresas, é mais comum o preço ser imposto pelo prestador de serviços do que pelo contratante. É possível, inclusive, que esta parcela seja maior do que aqui revelado, pois pode ter ocorrido que algumas empresas tenham externado mais um desejo do que o relato dos fatos propriamente ditos.

\section{REAJUSTES E REPACTUAÇÃO DE PREÇOS}

Ao contrário do que ocorre quando da definição dos valores iniciais, no momento da repactuação ambos os lados vêem-se um pouco presos diante da necessidade de estabelecer novos patamares de preços. Além das restrições contratuais, existe uma certa dependência bilateral, limitando, pelo menos em parte, as possibilidades de ambos os lados. Ademais, o poder de barganha pode passar por sucessivas variações ao longo do tempo.

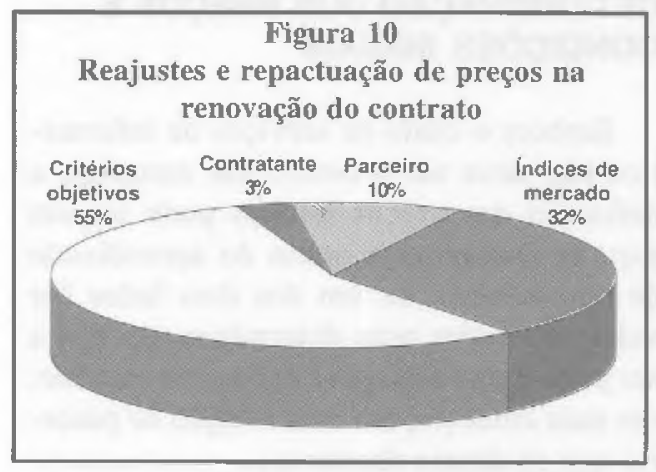

A figura 10 mostra que mais da metade das empresas declara que, no momento de renovar o contrato e reajustar preços, a discussão se faz com base em critérios objetivos, ou seja, considera-se o custo real dos serviços.

Note-se que a participação de índices de correção previamente determinados por contrato chega perto de um terço. A maioria destes índices é algo como variação cambial ou variação de preços, tipo IGP e similares. Ou seja, em grande parte é uma herança da cultura da indexação e, provavelmente, este tipo de encaminhamento deve apresentar participação relativa decrescente.

\section{SEGMENTOS DELEGADOS A TERCEIROS}

A terceirização em informática pode ser feita em diversos níveis, indo de um simples projeto estanque até a terceirização total. As empresas pesquisadas relatam experiências bastante diversificadas quanto aos segmentos da informática que foram ou estão em vias de ser delegados a terceiros (respostas múltiplas), como mostra a tabela 1 .

\section{Tabela 1}

Segmentos e serviços de informática delegados a parceiros externos

\begin{tabular}{|c|c|}
\hline Manutença de equipamentos & $89 \%$ \\
\hline Treinamento em microinformática & $87 \%$ \\
\hline Programação & $74 \%$ \\
\hline Manutençăo de sistemas & $62 \%$ \\
\hline Treinamento de usuários & $59 \%$ \\
\hline Projeto e desenvol vimento de sistemas & $58 \%$ \\
\hline Microfilmagem & $54 \%$ \\
\hline Suporte lécnico em sofrware & $51 \%$ \\
\hline Serviços de comunicação de dados & $50 \%$ \\
\hline Projeto de redes de teleprocessamento & $45 \%$ \\
\hline Digitação & $43 \%$ \\
\hline Análise e concep̧̧ão de sistemas & $34 \%$ \\
\hline $\begin{array}{l}\text { Recuperação de desastres } \\
\text { (planos de coutingência) }\end{array}$ & $30 \%$ \\
\hline Definição de metodologias & $29 \%$ \\
\hline Editoração eletrôuica & $26 \%$ \\
\hline Levantamentos e diagnósticos & $25 \%$ \\
\hline Processamento (inclusive time-sharing) & $19 \%$ \\
\hline Planejamento (PDI) & $13 \%$ \\
\hline Área de informática inteira & $5 \%$ \\
\hline Outros & $5 \%$ \\
\hline
\end{tabular}


Alguns aspectos da tabela 1 merecem ser comentados em detalhe:

- Equipes próprias de manutenção e treinamento em microinformática estão virtualmente desaparecendo. Talvez em menor grau, o mesmo ocorre com a programação, manutenção e desenvolvimento de sistemas. São nichos onde, tipicamente, o parceiro externo tende a ser mais competitivo, năo só no preço, como também nos recursos disponíveis para uso imediato.

- É surpreendente que os trabalhos de PDI e as atividades de levantamento e diagnósticos tenham participação tão tímida de terceiros. Tais nichos são particularmente indicados para serem delegados a um elemento neutro, inclusive como forma de assegurar isenção na avaliação e nas propostas.

- Outro nicho pouco terceirizado atualmente é o processamento (inclusive timesharing). Ao contrário do que ocorria no início da era da computação comercial, o fator restritivo não é mais o custo do computador: o hardware tornou-se tão barato que compensa mantê-lo internamente.

- Planos de contingência estão entre os itens mais frequientemente delegados a terceiros na Europa e nos Estados Unidos, ${ }^{12}$ mas ainda ocupam posição limitada no contexto brasileiro.

\section{BENEFÍCIOS ALCANÇADOS}

Talvez não se devesse falar de benefícios alcançados, mas percebidos. Não raro, os benefícios não são reconhecidos em sua plenitude, ofuscados por problemas menores. As empresas que estão terceirizando sua informática reconhecem que vêm obtendo diversos benefícios, conforme pode-se constatar na tabela 2 (respostas múltiplas).

A redução de custos, reconhecida por metade das otganizações, está longe de ser o benefício mais mencionado. O mais importante é que quatro em cada cinco empresas estão realmente conseguindo focalizar seus esforços, delegando a terceiros aquilo que não faz parte de seu core business.

Outros resultados percebidos pela maioria das empresas são: previsibilidade de gastos, objetividade na análise custo/benefício, agilidade na implementação de so-

\begin{tabular}{|l|c|}
\hline \multicolumn{2}{|c|}{ Tabela 2} \\
Resultados alcançados com a terceirização \\
\hline Focalização de esforços em atividades-fim & $80 \%$ \\
\hline $\begin{array}{l}\text { Previsibilidade dos gastos } \\
\text { (custos e investimentos) }\end{array}$ & $62 \%$ \\
\hline \begin{tabular}{l|l|}
\hline Objetividade na ańlise \\
custo versus benefício
\end{tabular} & $58 \%$ \\
\hline \begin{tabular}{l|l|}
\hline Agilidade na implementação de soluçôes \\
\hline Objetividade na definição de prioridades
\end{tabular} & $58 \%$ \\
\hline Redução de custos & $55 \%$ \\
\hline Previsibilidade de prazos & $52 \%$ \\
\hline $\begin{array}{l}\text { Outros (qualidade, acesso a novos } \\
\text { recursos e tecnologias etc.) }\end{array}$ & $10 \%$ \\
\hline
\end{tabular}

luções e objetividade na definição de prioridades. Todos estes pontos são, classicamente, origem de problemas quando se trabalha com equipes internas $e$, aparentemente, a terceirização tem sido um bom caminho para contorná-los.

\section{PROBLEMAS ENFRENTADOS}

Apesar dos benefícios alcançados, as empresas são obrigadas a conviver com algumas dificuldades. Embora em grau menor que o observado nos benefícios, são citados vários problemas, como mostia a tabela 3 (respostas múltiplas).

\begin{tabular}{|c|c|}
\hline $\begin{array}{c}\text { Tabela } 3 \\
\text { Problemas enfrentados como } \\
\text { conseqüência da terceirização }\end{array}$ & \\
\hline Resistência interna do pessoal técnico & $42 \%$ \\
\hline $\begin{array}{l}\text { Falta de capacitaçāo/qualificação } \\
\text { do parceiro }\end{array}$ & $41 \%$ \\
\hline Dificuldades com interfaces & $40 \%$ \\
\hline Pessoal interno não sabe lidar com terceiros & $32 \%$ \\
\hline Resistência interna dos usuários & $31 \%$ \\
\hline Perda do controle sobre a qualidade & $31 \%$ \\
\hline Perda de controle sobre os prazos & $29 \%$ \\
\hline $\begin{array}{l}\text { Cultura do parceiro não se } \\
\text { adapta ao padrão }\end{array}$ & $27 \%$ \\
\hline Falta de idoneidade do parceiro & $22 \%$ \\
\hline Reclamaçôes trabalhistas & $16 \%$ \\
\hline $\begin{array}{l}\text { Perda do controle da estratégia } \\
\text { de informatização }\end{array}$ & $13 \%$ \\
\hline Perda do controle sobre os custos & $12 \%$ \\
\hline Vazamento de informaçōes confidenciais & $10 \%$ \\
\hline
\end{tabular}


Três itens destacam-se num primeiro patamar com elevada incidência, em torno de 40\% das empresas: resistência do pessoal técnico interno, falta de qualificação/ capacitação do parceiro e dificuldades com interfaces. Nenhum desses temas chega a surpreender, mas, no conjunto, delineiase um quadro preocupante, principalmente por ser indício de falta de maturidade nesse mercado.

Logo a seguir, num segundo grupo, vêm a falta de preparo do usuário (que geralmente não está habituado ao trabalho com parceiros externos) e sua resistência ao processo. Também aparece neste segundo patamar a perda do controle sobre qualidade e prazos, assunto que ainda não foi adequadamente solucionado no contexto brasileiro.

\section{PRINCIPAIS PREOCUPAÇÕES QUANTO À TERCEIRIZAÇÃO EM INFORMÁTICA}

Ao final do questionário, foi apresentada uma lista de doze preocupações, que deveriam ser hierarquizadas em termos de importância, encontrando-se o resultado abaixo (apresentado em ordem decrescente de prioridades):

- A preocupação com a qualidade e o nível de serviço recebeu a prioridade máxima em $41 \%$ das respostas, seguida de longe pelo cuidado para se evitar a dependência, que recebeu apenas $17 \%$ dos votos.

- As preocupaçōes quanto a custos e prazos aparecem logo atrás, seguidas de per- to pelo problema do sigilo. A partir daí, praticamente todos os demais itens passam para um segundo plano.

\section{PLANOS PARA O FUTURO}

Identificados os benefícios e os problemas, a intenção quanto ao que se fará daqui por diante é o melhor indicativo da eficácia da terceirização enquanto solução para a informatização. Mesmo que não exista uma avaliação formal, se o saldo final não estiver sendo positivo, deve-se sentir a necessidade de reverter a situação. E, se tudo estiver correndo bem, provavelmente se considerará a hipótese de estender a experiência para outros nichos.

Ao serem inquiridas quanto aos planos para o futuro, um quinto das empresas declarou ainda não saber o que fazer daqui por diante. Parece lícito presumit que este grupo representa os casos que ainda nāo apresentam uma avaliação nítida sobre o balanço de prós e contras da terceirização.

Observando-se a figura 11, nota-se que, dentre os que já decidiram o que fazer, apenas uma em cada oito empresas pretende reverter o processo, enquanto que as outras sete pretendem intensificar ou, pelo menos, manter como está. Em outras palavras, para sete em cada oito empresas, o balanço final deve estar mostrando um saldo positivo. Ou, enunciado de outra forma, para cada insatisfeito há sete satisfeitos. Relato similar é apresentado pela revista Byte. ${ }^{13}$ Isto é um excepcional atestado da

Tabela 4

Principais preocupaçōes num processo de terceirização

1. Manter sob controle a qualidade e o nível de serviço fornecidos pelo parceiro.

2. Cuidado para evitar a criação de vínculos de dependência em relação ao parceiro.

3. Manter sob controle os custos dos serviços contratados.

4. Manter sob controle os prazos prometidos pelo parceiro.

5. Sigilo e confidencialidade das informaçōes em poder do parceiro.

6. Falta de padrōes do parceiro, ou inadequação de seus padrōes às exigências da organização.

7. Procedimentos alternativos caso venham a ocorrer problemas de relacionamento com o parceiro.

8. Validação do direcionamento estratégico adotado on proposto pelo parceiro.

9. Plano de contingência para casos de pane ou desastre nos equipamentos e instalaçōes do parceiro.

10. Possibilidade de se fazer auditoria nos procedimentos e instalaçōes do parceiro.

11. Evitar a subcontratação, em que o parceiro repassa, para outrem, o todo ou parte do serviço contratado.

12. Evitar a possibilidade de reclamaçôes trabalhistas por parte do parceiro oul de seus de empregados. 


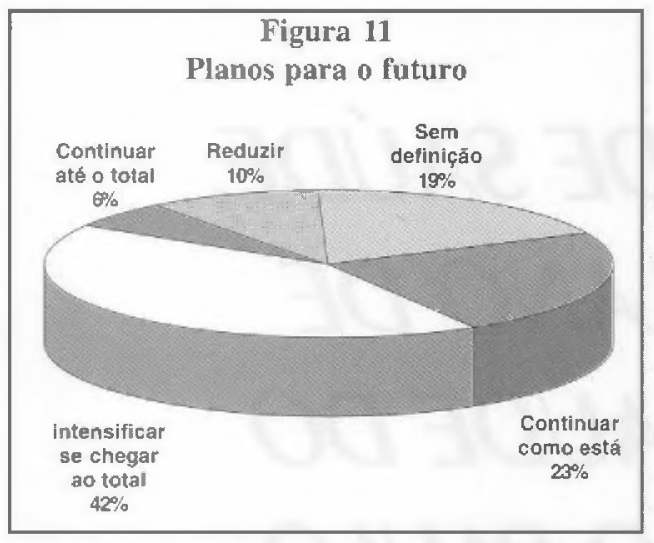

eficácia da terceirização em informática e, provavelmente, é a constatação mais importante desta pesquisa.

\section{CONCLUSÕES E COMENTÁRIOS FINAIS}

Dentre as principais conclusōes que se podem obter a partir desta pesquisa, destacam-se:

- no contexto brasileiro, a terceirizaçăo em informática vem tendo resultados bastante positivos, com uma média de sete empresas satisfeitas (que pretendem manter ou aumentar o processo) para cada uma insatisfeita (que pretende reverter a terceirização);

- a terceirização em informática ocupa cada vez mais espaço nas empresas brasileiras, mas a maioria dificilmente chegará à terceirização total;

- ainda que com eventuais percalços, as expectativas em geral estāo sendo alcançadas e a experiência está tendo um saldo final bastante positivo;

- o processo de construção e sustentação de parcerias já está razoavelmente maduro com relação à escolha de parceiros, redação do contrato e definição de preços iniciais;

- apesar do amadurecimento nos critérios para a escolha de parceiros, ainda ocorrem problemas ligados à falta de capacitação do prestador de serviços;

- a falta de definição prévia de uma política quanto à quantidade de parceiros é o fator crítico que se encontra em pior situação; a alta incidência de dificuldades com interfaces pode ser reflexo direto desta indefinição;
- a preparação interna (tanto do pessoal técnico como do usuário), que também é um fator crítico para o sucesso da terceirização, não está sendo adequadamente tratada, como se pode confirmar pela elevada incidência de problemas nesta área;

- o tratamento dispensado ao pessoal técnico interno atingido pelo processo parece estar caminhando em direção a uma maior maturidade, mas ainda persistem alguns problemas;

- as formas de definição de reajustes e repactuação de preços são um tópico que igualmente ainda carece de maturidade: são comuns os casos em que os preços são reajustados por índices de inflação, sem qualquer relação com os custos do serviço e o desenvolvimento tecnológico;

- reclamações trabalhistas não chegam a constituir um problema e, nem de longe, merecem a preocupação que frequientemente lhes é atribuída.

Em síntese, dos quatro fatores críticos para o sucesso da terceirização, dois deles estão bem encaminhados (escolha de parceiros e redação do contrato), embora com algumas deficiências. Os outros dois (preparação interna de usuários e profissionais de informática e estabelecimento de uma política quanto à quantidade de parceiros, decorrente da definição prévia de níveis de terceirização) ainda estão mal resolvidos no contexto brasileiro.

Algo que resta em aberto, para ser investigado mais de perto, é a questão do acompanhamento do processo. Năo chegaram a ser abordados vários aspectos relevantes, como auditoŗia e monitoração interna e externa, bem como a eventual problemática de rompimento e substituição de parceiros.

De uma forma ou de outra, ainda que reconhecidamente se enfrentem contratempos de naturezas diversas, parece ter ficado patente que a terceirização em informática é um processo irreversível, cujos resultados têm apresentado um balanço altamente positivo para aqueles que a abraçaram. Resta saber se os $20 \%$ que ainda não experimentaram esse recurso manterão sua posição independente ou se acabarão aderindo à tendência. 